\title{
Validation of a home food inventory among low-income Spanish- and Somali-speaking families
}

\author{
Mary $\bigcirc$ Hearst ${ }^{1, *}$, Jayne A Fulkerson ${ }^{2}$, Michelle Parke ${ }^{1,2}$ and Lauren Martin ${ }^{3}$ \\ 'Division of Epidemiology and Community Health, School of Public Health, University of Minnesota, 1300 South \\ Second Street, Suite 300, Minneapolis, MN 55454, USA: ${ }^{2}$ School of Nursing, University of Minnesota, \\ Minneapolis, MN USA: ${ }^{3}$ Urban Research and Outreach-Engagement Center, University of Minnesota, \\ Minneapolis, MN, USA
}

Submitted 17 January 2012: Final revision received 14 June 2012: Accepted 24 August 2012: First published online 4 October 2012

\begin{abstract}
Objective: To refine and validate an existing home food inventory (HFI) for low-income Somali- and Spanish-speaking families.

Design: Formative assessment was conducted using two focus groups, followed by revisions of the HFI, translation of written materials and instrument validation in participants' homes.

Setting: Twin Cities Metropolitan Area, Minnesota, USA.

Subjects: Thirty low-income families with children of pre-school age (fifteen Spanish-speaking; fifteen Somali-speaking) completed the HFI simultaneously with, but independently of, a trained staff member. Analysis consisted of calculation of both item-specific and average food group kappa coefficients, specificity, sensitivity and Spearman's correlation between participants' and staff scores as a means of assessing criterion validity of individual items, food categories and the obesogenic score.

Results: The formative assessment revealed the need for few changes/additions for food items typically found in Spanish-speaking households. Somali-speaking participants requested few additions, but many deletions, including frozen processed food items, non-perishable produce and many sweets as they were not typical food items kept in the home. Generally, all validity indices were within an acceptable range, with the exception of values associated with items such as 'whole wheat bread' $(\kappa=0 \cdot 16)$. The obesogenic score (presence of high-fat, high-energy foods) had high criterion validity with $\kappa=0 \cdot 57$, sensitivity $=91 \cdot 8 \%$, specificity $=70 \cdot 6 \%$ and Spearman correlation $=0 \cdot 78$.

Conclusions: The revised HFI is a valid assessment tool for use among Spanish and Somali households. This instrument refinement and validation process can be replicated with other population groups.
\end{abstract}

According to the Dietary Guidelines for Americans, children are consuming more energy than their daily needs which is contributing to obesity among this population ${ }^{(1)}$. Currently, up to $15 \%$ of pre-school children are overweight or obese $^{(2)}$. Overweight or obesity in childhood persists into adolescence and adulthood ${ }^{(3,4)}$, carrying with it risk factors for CVD, diabetes, psychological distress and other health consequences $^{(3-5)}$. Children from low-income, minority families are more likely to be overweight or obese and face more obesity-related risk than children from higherincome, non-minority families ${ }^{(6,7)}$. This health disparity is at least partially attributed to limited home access to healthy foods ${ }^{(2,6)}$.

The home environment is the primary environmental exposure to food and food practices for children of pre-school age ${ }^{(7-9)}$. Children's individual consumption of specific foods such as fruits, vegetables and high- or low-fat foods has been directly associated with the food available in the home ${ }^{(10-13)}$. The availability of less healthful foods, such as sugar-sweetened beverages, candy and salty snacks, is directly related to their intakes of those items and inversely related to overall fruit and vegetable intake ${ }^{(14,15)}$. Furthermore, owing to easy home access ${ }^{(16)}$, soda consumption is one of the largest contributors to energy intake in children ${ }^{(17)}$. As children's diets fall short of meeting dietary recommendations across food groups ${ }^{(18)}$, the home food environment is an important environment to target for improvement.

One efficient tool that has been used to assess the home food environment is a home food inventory (HFI). Many HFI exist ${ }^{(19)}$, but we found none that are validated for non-English-speaking, minority populations. Only one 
study has assessed a food inventory specific to lowincome populations ${ }^{(20)}$. Criterion validity (comparison of the measurement with a 'gold standard') of such measures has been shown in five studies ${ }^{(11,13,21-23)}$ and construct validity (the tool measures what was intended) has been shown in three ${ }^{(11,13,23)}$ (see Fulkerson et al. ${ }^{(13)}$ and Pinard et $a l^{(24)}$ for reviews). The usefulness of the majority of inventories is limited due to inclusion of a narrow range of foods or because they include only specific foods to assess a targeted outcome (e.g. fruit and vegetable intake on cancer risk $)^{(19)}$. However, one HFI tool developed and validated by Fulkerson et $a l .{ }^{(13)}$ can easily be completed by research participants and contains a wide variety of foods, healthful and less healthful, that are associated with obesity. One limitation of the Fulkerson HFI and a general gap in the literature is the lack of validation among ethnically diverse populations. The cultural relevance of an HFI such as this is needed to ensure valid home food environment data collection for diverse populations, especially racial and ethnic minorities, including recent immigrants, who face increased health disparities associated with nutrition, dietary intake and obesity.

The purpose of the present study was to develop and validate an HFI for low-income, non-English-speaking families. Somali and Hispanic immigrant populations continue to grow in the USA and their obesity-related risk factors are on the rise. An accurate and culturally relevant assessment of the home food environment is important for obesity prevention and health promotion in these communities. Creating a healthy home food environment and educating parents are vital to the short- and longterm health of children. The present study provides an example of the process taken to validate the HFI in Somali and Hispanic families because they are growing racial/ethnic minorities in the Twin Cities, Minnesota area. However, the methods and findings presented could inform a similar validation with other populations of interest in other communities nationally.

\section{Methods}

The study was conducted in two phases. First, separate focus groups were conducted with Spanish- and Somalispeaking parents of young children. Second, a total of thirty additional Spanish- and Somali-speaking low-income families were recruited to complete the HFI at the same time as, but independently of, study staff (criterion validation phase). The two phases, procedures, study populations and measures are described below. The research was approved by the University of Minnesota Institutional Review Board.

\section{Home food inventory}

The HFI is a checklist. Food items, grouped according to category, are listed with a yes/no response option. For illustration, the HFI has a category for 'milk/dairy', under which is listed items including 'whole milk', '2\% milk', ' $1 \%$ milk', 'skim milk', 'chocolate milk', 'soy milk', etc. If the item is present in the home, wherever there is food stored in the home, the participant checks the 'yes' box. If the item is not present, the participant checks the 'no' box. Categories included dairy (cheese; milk/other dairy; yoghurt; other), all vegetables and fruits (fresh, frozen, dried or canned), meats and other non-dairy protein, added fat, frozen desserts, prepared desserts, savoury snacks, microwavable/quick-cook foods, bread, candy, cereals and beverages. In addition, selected items were assessed for accessibility, meaning the items were present on the kitchen counter or visual when opening the refrigerator door. Additional details about the HFI can be found elsewhere ${ }^{(13)}$.

\section{Focus groups}

Two focus groups were conducted. One focus group included five Hispanic participants bilingual in Spanish and English (five females) and the second focus group included five Somali adults (one male, four females) with English language skills. The focus groups were conducted by bilingual staff members trained in focus group facilitation. Although the focus groups were conducted in English, a bilingual facilitator was important for clarification of words or concepts in the participant's native language. Adults were recruited with support of community organization partnerships using a convenience sample, although fitting the inclusion criteria of ethnicity and having children of pre-school age. Each focus group included a consent procedure, introduction and three questions. The facilitators asked: (i) 'What are some of the foods you typically have in your house?'; (ii) 'What kind of foods do you think influence your weight?'; and (iii) 'Let's talk about homemade $v$. prepackaged foods - how would you describe them and what are your thoughts and opinions about ingredients?'. This final question was important to gain insight into purchasing decisions that influence what is available in the home. Finally, participants were asked to review and complete the HFI validated by Fulkerson et al. ${ }^{(13)}$, to indicate foods that they typically had in their homes, cross off items they never have in their homes and add any items that are common but were not listed on the original form. The purpose of this phase was to modify the form as it relates to potential cultural food preferences. The HFI survey was modified accordingly by eliminating or adding items. A note taker was present and the conversation was tape recorded at both sessions. Participants were provided with a \$US 30 gift card to a local food store and child care was provided.

\section{Translation}

The revised HFI, consent forms and survey items (described below) were translated into Spanish and Somali prior to the validation portion of the study. 


\section{Validation component}

The same bilingual staff members who conducted the focus groups recruited an additional thirty families (fifteen Spanish-speaking parents and fifteen Somalispeaking parents) to participate in the validation phase of the study. Inclusion criteria were Spanish or Somali ethnicity, low income (loosely defined as eligible for community services) and presence of children under the age of 5 years in the home. Spanish-speaking families were primarily recruited from North Minneapolis, a neighbourhood defined as low-income and ethnically diverse. Somali-speaking families were recruited from a larger geographic area in Minneapolis. With the family's permission, an appointment was made and the staff member and another study representative visited the home. The family completed a consent process, including signed consent forms, was provided with directions on how to complete the HFI (in the language of preference) and instructed to not talk with the staff member while completing the form.

\section{Data analysis}

Data analysis occurred in two phases. The focus groups were tape recorded with a note taker present. Key themes and comments were noted during the focus group. The primary outcome from the focus groups was the editing of the HFI. A new version of the HFI was created based on the additions and deletions recommended by the participants. An item was added to the new HFI tool if at least one participant recommended the additional food item. An item was deleted only if all five participants recommended deleting the item(s) or reported never having the particular food item(s) in their homes.

Once the criterion validity data collection was completed, HFI validation data were entered into a Microsoft ${ }^{\circledR}$ Excel spreadsheet as 1/0 values for each food item. Data were imported into the statistical software package SAS version $9 \cdot 1$ for Windows. Given the small sample size ( $n$ 30) and risk of zero cells (i.e. neither staff nor participant reported item present in home), we conducted analyses both stratified by ethnicity and with the two groups combined. We assessed criterion validity, by comparing participants' and trained research staff assessments using identical HFI tools. We calculated kappa coefficients, specificity (proportion of participant/staff dyads reporting item not present), sensitivity (proportion of participant/staff dyads reporting item as present) and Spearman correlations for each of the individual items. Next, we averaged the individual item scores according to the larger food category, such as 'dairy' as opposed to an individual item of ' $1 \%$ milk'. A summary score was calculated to represent the overall obesogeneity of the home food items. This summative score included regular-fat versions of cheese, milk, yoghurt, other dairy, frozen desserts, prepared desserts, savoury snacks, added fats, regular sugar-sweetened beverages, processed meat, high-fat quick foods and access to unhealthy foods in the refrigerator and kitchen. The inventory took 30-60 min to complete depending upon participant literacy.

\section{Results}

\section{Focus groups}

The primary outcome of the focus groups was an edited HFI tool; therefore, we highlight the results on this aspect of the focus group. Participants required 20-30 min to look through the list of food items on the HFI and consider if the foods were at least sometimes available in their households.

The Somali participants reported that foods typically found in their homes and Somali homes in general are homemade. 'Homemade' was an important aspect of their culture, partly because they do not know how long the food has been in the freezer and are not certain about ingredients. The Somali participants were firm on the limited use of pre-packaged and prepared foods in the home. Participants agreed that they can better manage balancing salt and fat content, and assure there are no pork products in the meal (to meet religious practices) if the food is homemade. Therefore, participants recommended removing all microwavable/quick-cook foods and many other pre-packaged items, including frozen vegetables. Additionally, participants reported it was not a cultural practice to typically have sweets and snacks in the home. Finally, Somali households do not typically contain a large variety of cheeses, so this category was reduced. Similarly, the Somali families had very few vegetables in the home and were unfamiliar with many of the vegetables available in the Twin Cities region. In addition to the recommendation to remove food items that contained pork (ham, sausage), Somali participants recommended adding goat meat, halwa and anjera to the HFI, all of which were commonly reported food items.

The Spanish-speaking participants had few recommended changes to the HFI. In fact, they did not recommend removing any items. The participants raised issues with their cultural dietary practices, including a traditionally high-fat (frying and use of lard in cooking) and carbohydrate-based diet. Participants also discussed the cultural role of 'homemade' foods, but stated that the use of homemade foods over pre-packaged or prepared foods decreases over time the longer a person is in the USA. In addition, Spanish-speaking families were concerned that the way they prepare their foods causes obesity, yet they struggle with time demands, work shift complications related to mealtimes and the food preferences of their children. Participants suggested adding Mexican fresh cheese, balsamic vinegar in the salad dressing section, zucchini, kale, leeks, onion and radish under vegetables, garlic, a variety of nuts, and Goldfish crackers specifically as it is a common snack food item. 


\section{Validation}

Thirty families, fifteen Somali- and fifteen Spanish-speaking, were successfully recruited to complete the HFI validation. Table 1 presents the sample characteristics of those who participated in the HFI validation component. The Spanishspeaking families had fewer resources in general than did the Somali families. Ten out of fifteen Somali families had their own car, but only five out of fifteen Spanish-speaking families had their own car. None of the Spanish-speaking families spoke English at home, two-thirds reported an annual income of less than \$US 20000, and only four out of fifteen reported that they had enough food to eat. Somali families generally reported higher annual income, enough food to eat, and three out of fifteen spoke English at home.

Table 1 Demographic characteristics of the total sample and stratified by group: low-income Somali- and Spanish-speaking families with children of pre-school age, Twin Cities Metropolitan Area, MN, USA

\begin{tabular}{|c|c|c|c|c|c|}
\hline & \multirow{2}{*}{$\frac{\text { Total }}{n}$} & \multicolumn{2}{|c|}{ Somali } & \multicolumn{2}{|c|}{ Spanish } \\
\hline & & $n$ & $\%$ & $n$ & $\%$ \\
\hline \multicolumn{6}{|l|}{ Primary transportation } \\
\hline Own car & 15 & 10 & $66 \cdot 7$ & 5 & $33 \cdot 3$ \\
\hline Someone else's car in home & 6 & 1 & $16 \cdot 7$ & 5 & $83 \cdot 3$ \\
\hline Someone else's car not in home & 1 & 1 & $100 \cdot 0$ & 0 & - \\
\hline Bus & 8 & 3 & $37 \cdot 5$ & 5 & $62 \cdot 5$ \\
\hline \multicolumn{6}{|l|}{ Main language at home } \\
\hline English & 3 & 3 & $100 \cdot 0$ & 0 & - \\
\hline Spanish & 15 & 0 & - & 15 & $100 \cdot 0$ \\
\hline Somali & 12 & 12 & $100 \cdot 0$ & 0 & - \\
\hline \multicolumn{6}{|l|}{ No. of children aged $<5$ years } \\
\hline 0 & 1 & 0 & - & 1 & $100 \cdot 0$ \\
\hline 1 & 12 & 6 & $50 \cdot 0$ & 6 & $50 \cdot 0$ \\
\hline 2 & 12 & 7 & $58 \cdot 3$ & 5 & $41 \cdot 7$ \\
\hline 3 & 4 & 2 & $50 \cdot 0$ & 2 & $50 \cdot 0$ \\
\hline 4 & 1 & 0 & - & 1 & $100 \cdot 0$ \\
\hline \multicolumn{6}{|l|}{ No. of children aged $5-17$ years } \\
\hline 0 & 13 & 8 & $61 \cdot 5$ & 5 & $38 \cdot 5$ \\
\hline 1 & 6 & 2 & $33 \cdot 3$ & 4 & $66 \cdot 7$ \\
\hline 2 & 6 & 2 & $33 \cdot 3$ & 4 & $66 \cdot 7$ \\
\hline 3 & 2 & 2 & $100 \cdot 0$ & 0 & - \\
\hline 4 & 3 & 1 & $33 \cdot 3$ & 2 & $66 \cdot 7$ \\
\hline \multicolumn{6}{|l|}{ No. of adults in the home } \\
\hline 1 & 6 & 6 & $100 \cdot 0$ & 0 & - \\
\hline 2 & 18 & 7 & $38 \cdot 9$ & 11 & $61 \cdot 1$ \\
\hline 3 & 4 & 1 & $25 \cdot 0$ & 3 & $75 \cdot 0$ \\
\hline 4 & 2 & 1 & $50 \cdot 0$ & 1 & $50 \cdot 0$ \\
\hline \multicolumn{6}{|l|}{ Annual household income (\$US) } \\
\hline $0-10000$ & 6 & 3 & $50 \cdot 0$ & 3 & $50 \cdot 0$ \\
\hline $10001-20000$ & 9 & 2 & $22 \cdot 2$ & 7 & $77 \cdot 8$ \\
\hline $20001-30000$ & 9 & 5 & $55 \cdot 6$ & 4 & $44 \cdot 4$ \\
\hline $30001-40000$ & 2 & 2 & $100 \cdot 0$ & 0 & - \\
\hline $40001-50000$ & 1 & 1 & $100 \cdot 0$ & 0 & - \\
\hline$>50000$ & 1 & 1 & $100 \cdot 0$ & 0 & - \\
\hline \multicolumn{6}{|l|}{ Level education } \\
\hline Less than high school & 13 & 6 & $46 \cdot 15$ & 7 & $53 \cdot 85$ \\
\hline High school/GED & 13 & 6 & $46 \cdot 15$ & 7 & $53 \cdot 85$ \\
\hline Some college & 2 & 2 & $100 \cdot 0$ & 0 & - \\
\hline Graduate degree & 1 & 1 & $100 \cdot 0$ & 0 & - \\
\hline \multicolumn{6}{|l|}{ Amount of food in household } \\
\hline Enough & 19 & 15 & $79 \cdot 0$ & 4 & $21 \cdot 0$ \\
\hline Sometimes not enough & 9 & 0 & - & 9 & $100 \cdot 0$ \\
\hline Often not enough & 1 & 0 & - & 1 & $100 \cdot 0$ \\
\hline
\end{tabular}

GED, General Educational Development.
Table 2 presents the average scores across major and subgroup food items for the total sample and separated by Somali- and Spanish-speaking populations. Individual items are not presented given the large number of items. Overall findings include the following (for the total sample): $\kappa$ coefficients ranged from $0 \cdot 16$ (whole wheat bread) to $0 \cdot 85$ (microwavable/quick-cook foods); sensitivity ranged from $35 \cdot 3 \%$ (whole wheat bread) to $96 \cdot 8 \%$ (microwavable/ quick-cook foods); and specificity ranged from $35 \cdot 3 \%$ (whole wheat bread) to $100 \%$ (regular-fat frozen dessert). Finally, Spearman correlation coefficients ranged from $0 \cdot 20$ (low-fat cheese) to $0 \cdot 88$ (milk/other dairy). The obesogenic score had $\kappa=0.57$, sensitivity $=91 \cdot 8 \%$, specificity $=$ $70 \cdot 6 \%$ and Spearman correlation $=0 \cdot 78$.

\section{Discussion}

The primary aim of the present study was to refine and validate an HFI for low-income, non-English-speaking families. Our method was effective in tailoring an existing HFI tool for use in specific cultural groups. The HFI was validated, using criterion validity, with Spanish- and Somalispeaking families with a few caveats. A unique HFI can be used for subpopulations, or specific modifications can be made to the parent HFI and used across populations. For example, by adding the participant-recommended food items (e.g. Mexican fresh cheese, balsamic vinegar, goat meat and anjera), the HFI can be effectively used for non-Hispanic white, Hispanic and Somali study participants. A similar procedure was effectively used to assess the availability of culturally preferred foods from area food stores $^{(25)}$ and, thus, highlights how existing instruments can be revised to be more culturally relevant. The researchers used an interview process to modify an existing community food availability tool to capture culturally preferred foods among African-American and Latino participants ${ }^{(25)}$ supporting the rationale for accounting for cultural food preferences when assessing the food environment. Researchers need to keep in mind that given the lower variety of food items in Somali homes and the low number of items in food-insecure homes, the full survey with all of the items will increase the burden to families and should be acknowledged.

Second, we learned that validation was less accurate for items more difficult to differentiate. For example, there was low validity for 'whole wheat bread' between the participant and the 'gold standard' staff member. However, items such as frozen pizza and chicken nuggets had high validity. A similar issue was reported in the validation study of the original $\mathrm{HFI}^{(13)}$. It has been documented in the literature that consumers' knowledge of food nutrients and ability to read a food nutrient label are limited at best ${ }^{(26,27)}$. A PubMed literature search of food nutrient label and minority/immigrant/Spanish revealed no citations, although one article was found related to Chinese immigrants 
Table 2 Inventory major and subgroup category criterion validity indices for the total sample $(n 30)$ and by group: low-income Somali- and Spanish-speaking families with children of pre-school age, Twin Cities Metropolitan Area, MN, USA

\begin{tabular}{|c|c|c|c|c|c|c|c|c|c|c|c|c|}
\hline & \multicolumn{3}{|c|}{ Average $\kappa$ for category } & \multicolumn{3}{|c|}{ Sensitivity (\%) } & \multicolumn{3}{|c|}{ Specificity (\%) } & \multicolumn{3}{|c|}{ Spearman correlation staff/participant } \\
\hline & $\begin{array}{l}\text { Total } \\
(n 30)\end{array}$ & $\begin{array}{c}\text { Spanish } \\
(n 15)\end{array}$ & $\begin{array}{l}\text { Somali } \\
(n 15)\end{array}$ & $\begin{array}{l}\text { Total } \\
(n 30)\end{array}$ & $\begin{array}{c}\text { Spanish } \\
(n 15)\end{array}$ & $\begin{array}{l}\text { Somali } \\
(n 15)\end{array}$ & $\begin{array}{l}\text { Total } \\
(n 30)\end{array}$ & $\begin{array}{c}\text { Spanish } \\
(n 15)\end{array}$ & $\begin{array}{l}\text { Somali } \\
(n 15)\end{array}$ & $\begin{array}{c}\text { Total } \\
(n 30)\end{array}$ & $\begin{array}{c}\text { Spanish } \\
(n 15)\end{array}$ & $\begin{array}{l}\text { Somali } \\
(n \text { 15) }\end{array}$ \\
\hline Dairy & 0.55 & $0 \cdot 40$ & 0.82 & $89 \cdot 9$ & $86 \cdot 8$ & $97 \cdot 1$ & $78 \cdot 1$ & $57 \cdot 9$ & $87 \cdot 0$ & 0.77 & 0.36 & 0.84 \\
\hline Cheese & 0.53 & 0.41 & 0.97 & $77 \cdot 1$ & $87 \cdot 8$ & $99 \cdot 0$ & $77 \cdot 1$ & $56 \cdot 9$ & $97 \cdot 2$ & 0.78 & 0.32 & 0.97 \\
\hline Regular fat & 0.53 & 0.38 & 0.95 & $73 \cdot 3$ & $84 \cdot 3$ & $100 \cdot 0$ & $73 \cdot 3$ & $50 \cdot 7$ & $96 \cdot 3$ & 0.82 & 0.33 & 0.96 \\
\hline Low fat & 0.47 & 0.53 & 1.00 & $100 \cdot 0$ & 94.9 & $100 \cdot 0$ & $100 \cdot 0$ & $100 \cdot 0$ & $100 \cdot 0$ & 0.20 & 0.30 & $1 \cdot 0$ \\
\hline Milk/other dairy beverages & 0.63 & 0.54 & 0.88 & $88 \cdot 9$ & $88 \cdot 6$ & 98.5 & 88.9 & $64 \cdot 2$ & $95 \cdot 8$ & 0.88 & 0.54 & 0.89 \\
\hline Regular fat & 0.58 & 0.53 & 0.87 & $92 \cdot 3$ & $91 \cdot 9$ & $100 \cdot 0$ & $92 \cdot 3$ & $60 \cdot 0$ & $87 \cdot 5$ & 0.60 & 0.53 & 0.88 \\
\hline Reduced fat & 0.62 & 0.33 & 0.81 & $71 \cdot 2$ & $72 \cdot 4$ & $97 \cdot 4$ & $71 \cdot 2$ & $47 \cdot 0$ & $86 \cdot 7$ & 0.74 & 0.33 & 0.83 \\
\hline Yoghurt & 0.53 & 0.20 & 0.91 & $64 \cdot 8$ & $89 \cdot 1$ & $88 \cdot 6$ & $64 \cdot 8$ & 33.3 & 82.5 & 0.71 & 0.21 & 0.73 \\
\hline Regular fat & 0.67 & $0 \cdot 62$ & 0.73 & $76 \cdot 5$ & 100 & $85 \cdot 7$ & $76 \cdot 5$ & $66 \cdot 7$ & $87 \cdot 5$ & 0.68 & 0.67 & 0.73 \\
\hline Reduced fat & 0.46 & -0.01 & 0.70 & $59 \cdot 0$ & $83 \cdot 7$ & $90 \cdot 0$ & $59 \cdot 0$ & $16 \cdot 7$ & $80 \cdot 0$ & 0.48 & -0.02 & 0.73 \\
\hline Other dairy & 0.28 & $0 \cdot 16$ & 0.44 & $80 \cdot 0$ & $77 \cdot 0$ & $100 \cdot 0$ & $80 \cdot 0$ & $55 \cdot 6$ & 33.3 & 0.80 & $0 \cdot 20$ & 0.53 \\
\hline Regular fat & 0.24 & 0.07 & 0.44 & $60 \cdot 0$ & $76 \cdot 2$ & $100 \cdot 0$ & $60 \cdot 0$ & $33 \cdot 3$ & $33 \cdot 3$ & 0.52 & 0.08 & 0.53 \\
\hline Reduced fat & 0.35 & 0.33 & - & $100 \cdot 0$ & $78 \cdot 6$ & $100 \cdot 0$ & $100 \cdot 0$ & $100 \cdot 0$ & $100 \cdot 0$ & 0.46 & 0.44 & $1 \cdot 0$ \\
\hline Added fat & 0.50 & 0.36 & 0.64 & $90 \cdot 7$ & $78 \cdot 1$ & $92 \cdot 8$ & $71 \cdot 7$ & $67 \cdot 4$ & $70 \cdot 9$ & 0.65 & 0.37 & 0.66 \\
\hline Regular fat & 0.56 & 0.38 & 0.69 & $72 \cdot 7$ & $68 \cdot 1$ & $94 \cdot 0$ & $72 \cdot 7$ & $76 \cdot 1$ & $75 \cdot 4$ & 0.62 & 0.38 & $0 \cdot 72$ \\
\hline Reduced fat & 0.38 & 0.32 & 0.47 & $69 \cdot 0$ & $94 \cdot 2$ & $90 \cdot 6$ & $69 \cdot 0$ & $50 \cdot 0$ & $55 \cdot 0$ & 0.32 & 0.33 & 0.48 \\
\hline Vegetables & 0.64 & 0.59 & 0.71 & $84 \cdot 0$ & $79 \cdot 9$ & $92 \cdot 8$ & $84 \cdot 5$ & 81.9 & $84 \cdot 2$ & 0.69 & $0 \cdot 61$ & 0.73 \\
\hline Vegetables no potatoes & 0.64 & 0.58 & 0.73 & $83 \cdot 2$ & 78.9 & $92 \cdot 4$ & $84 \cdot 2$ & $81 \cdot 3$ & $84 \cdot 0$ & 0.67 & 0.61 & 0.74 \\
\hline Fruit & 0.58 & 0.54 & 0.92 & $92 \cdot 7$ & $86 \cdot 2$ & $98 \cdot 5$ & $87 \cdot \overline{9}$ & 81.9 & $96 \cdot 3$ & 0.76 & 0.58 & 0.93 \\
\hline All protein & 0.51 & .038 & 0.59 & $88 \cdot 2$ & $79 \cdot 5$ & $96 \cdot 0$ & $76 \cdot 2$ & $68 \cdot 6$ & $73 \cdot 8$ & 0.57 & 0.42 & 0.62 \\
\hline Processed meats & 0.66 & 0.64 & 0.63 & $75 \cdot 0$ & $94 \cdot 2$ & $100 \cdot 0$ & $75 \cdot 0$ & $76 \cdot 7$ & $50 \cdot 0$ & 0.75 & 0.65 & 0.68 \\
\hline All other protein & 0.48 & 0.30 & 0.58 & $81 \cdot 1$ & $72 \cdot \overline{5}$ & $96 \cdot 1$ & $81 \cdot 1$ & $70 \cdot 5$ & $73 \cdot 4$ & 0.37 & 0.34 & 0.60 \\
\hline Frozen desserts & 0.58 & 0.46 & 0.72 & $94 \cdot 3$ & $92 \cdot 6$ & $94 \cdot 8$ & $75 \cdot 0$ & $70 \cdot 0$ & $100 \cdot 0$ & 0.85 & 0.48 & 0.77 \\
\hline Regular fat & 0.85 & $0 \cdot 71$ & 1.00 & $100 \cdot 0$ & $90 \cdot 9$ & $100 \cdot 0$ & $100 \cdot 0$ & $100 \cdot 0$ & $100 \cdot 0$ & 0.87 & 0.74 & 1.00 \\
\hline Reduced fat & 0.31 & $0 \cdot 21$ & 0.44 & $50 \cdot 0$ & $93 \cdot 3$ & $93 \cdot 0$ & $50 \cdot 0$ & $40 \cdot 0$ & $100 \cdot 0$ & 0.31 & 0.21 & 0.53 \\
\hline Microwavable/quick-cook foods & 0.85 & 0.88 & 0.81 & $96 \cdot 8$ & $97 \cdot 5$ & 88.6 & $84 \cdot 7$ & $92 \cdot 0$ & $93 \cdot 3$ & 0.81 & 0.88 & 0.82 \\
\hline Bread & 0.55 & 0.52 & 0.39 & $89 \cdot 4$ & $92 \cdot 1$ & $88 \cdot 5$ & $72 \cdot 2$ & $70 \cdot 9$ & $72 \cdot 2$ & 0.52 & 0.56 & 0.46 \\
\hline Whole wheat & $0 \cdot 16$ & $0 \cdot 13$ & 0.22 & $35 \cdot 3$ & $70 \cdot 6$ & $74 \cdot 7$ & $35 \cdot 3$ & $40 \cdot 0$ & $33 \cdot 3$ & 0.36 & 0.14 & 0.27 \\
\hline White & 0.61 & 0.61 & 0.43 & $78 \cdot 1$ & $97 \cdot 4$ & $83 \cdot 1$ & $78 \cdot 1$ & $67 \cdot 9$ & $83 \cdot 3$ & 0.65 & 0.65 & 0.49 \\
\hline Prepared desserts & 0.58 & 0.38 & 0.85 & $95 \cdot 3$ & $93 \cdot 8$ & $95 \cdot 8$ & $68 \cdot 8$ & $47 \cdot 2$ & $100 \cdot 0$ & 0.71 & 0.39 & 0.87 \\
\hline Regular fat & 0.61 & 0.38 & 0.91 & $68 \cdot 8$ & $91 \cdot 8$ & $97 \cdot 1$ & $68 \cdot 8$ & $47 \cdot \overline{2}$ & $100 \cdot 0$ & 0.71 & 0.39 & 0.91 \\
\hline Reduced fat & - & - & - & - & - & - & - & - & - & - & - & - \\
\hline Savoury snacks & 0.65 & 0.55 & 0.66 & $95 \cdot 0$ & $94 \cdot 2$ & $97 \cdot 8$ & $76 \cdot 3$ & 81.5 & $67 \cdot 1$ & 0.69 & 0.60 & 0.67 \\
\hline Regular fat & 0.60 & 0.55 & 0.57 & $69 \cdot 6$ & $91 \cdot 3$ & $96 \cdot 7$ & $69 \cdot 6$ & $77 \cdot 6$ & 58.9 & 0.61 & 0.60 & 0.59 \\
\hline Reduced fat & 0.67 & 0.50 & 0.50 & $75 \cdot 0$ & $85 \cdot 6$ & $75 \cdot 0$ & $75 \cdot 0$ & $66 \cdot 7$ & $50 \cdot 0$ & 0.68 & 0.52 & 0.50 \\
\hline Beverages & 0.69 & 0.66 & 0.74 & $91 \cdot 4$ & $90 \cdot 4$ & $89 \cdot 8$ & $83 \cdot 0$ & $85 \cdot 1$ & $88 \cdot 1$ & 0.61 & 0.69 & 0.74 \\
\hline Regular sugar & 0.71 & 0.79 & 0.76 & $81 \cdot 7$ & $97 \cdot 2$ & $90 \cdot 7$ & $81 \cdot 7$ & $90 \cdot 5$ & $90 \cdot 0$ & 0.64 & 0.81 & 0.76 \\
\hline Low sugar & 0.66 & 0.54 & 0.70 & 84.9 & $81 \cdot 9$ & $87 \cdot 5$ & 84.9 & $79 \cdot 6$ & $85 \cdot 4$ & 0.69 & 0.56 & 0.70 \\
\hline \multicolumn{13}{|l|}{ Dry breakfast cereal } \\
\hline Low sugar & 0.51 & 0.25 & - & - & - & - & - & - & - & 0.69 & 0.49 & 0.89 \\
\hline High sugar & $0 \cdot 41$ & $0 \cdot 16$ & - & - & - & - & - & - & - & 0.52 & 0.07 & 0.81 \\
\hline Kitchen accessibility & 0.29 & $0 \cdot 13$ & 0.41 & $80 \cdot 4$ & $78 \cdot 1$ & $86 \cdot 1$ & $56 \cdot 7$ & $49 \cdot 6$ & $81 \cdot 6$ & 0.28 & $0 \cdot 15$ & 0.47 \\
\hline Access to healthy foods & 0.26 & $0 \cdot 13$ & 0.31 & $58 \cdot 4$ & 88.9 & $88 \cdot 1$ & $58 \cdot 4$ & $48 \cdot 5$ & $100 \cdot 0$ & 0.25 & $0 \cdot 17$ & 0.43 \\
\hline Access to unhealthy foods & 0.29 & $0 \cdot 13$ & 0.46 & $56 \cdot 7$ & $69 \cdot 1$ & $84 \cdot 3$ & $56 \cdot 7$ & $50 \cdot 0$ & $72 \cdot 5$ & 0.28 & $0 \cdot 14$ & 0.48 \\
\hline Refrigerator accessibility & 0.45 & $0 \cdot 47$ & 0.47 & $83 \cdot 2$ & 81.9 & $84 \cdot 7$ & $66 \cdot 7$ & $71 \cdot 1$ & $66 \cdot 0$ & 0.33 & 0.53 & 0.48 \\
\hline Access to healthy foods & 0.42 & 0.52 & 0.41 & $70 \cdot 3$ & $77 \cdot 6$ & $92 \cdot 4$ & $70 \cdot 3$ & $88 \cdot 3$ & 71.9 & 0.31 & $0 \cdot 46$ & 0.41 \\
\hline Access to unhealthy foods & 0.51 & 0.42 & 0.56 & $61 \cdot 0$ & $90 \cdot 4$ & $86 \cdot 1$ & $61 \cdot 0$ & $50 \cdot 3$ & $81 \cdot 6$ & 0.52 & $0 \cdot 15$ & 0.60 \\
\hline Obesogenic food availability score & 0.57 & 0.48 & 0.71 & $91 \cdot 8$ & 89.7 & 93.1 & $70 \cdot 6$ & 65.0 & 79.9 & 0.78 & 0.50 & 0.73 \\
\hline
\end{tabular}


to Canada $^{(28)}$. The combination of low population-wide understanding on nutrition labels, added to the language and literacy barriers among immigrant populations in particular, is the likely reason for less accuracy for items that contain 'whole wheat', for example. There was also relatively low validation of kitchen accessibility. These items asked participants to look on the counter, table and in the refrigerator and indicate what is observed - items sitting out in plain view have higher accessibility. It is not clear why there is lower validation of this particular measure and this requires further qualitative research. Perhaps there are cultural differences in the storage of food in homes. However, we found that there was good criterion validity for the obesogenic score suggesting that a universal examination of the food environment may provide a better snapshot of the healthfulness of the home food environment compared with examining individual items.

Third, we learned that the literacy of the population must be taken into account. The Somali families spoke Somali, but did not necessarily read Somali and required additional support for translation. The HFI may need to be completed verbally in some circumstances. In addition, some food items were either difficult to translate or unfamiliar to Somali families in particular. Future research and tool development in this area should adopt the HFI into technology where families can document the presence of an item using a computer or smart-pad that includes a feature linking the food item to photographs. This will be particularly useful among recent immigrants who are still eating their native diet and are unfamiliar with local produce ${ }^{(29)}$.

Factors limiting the value of examining the home food environment as an obesogenic exposure include the timing of shopping compared with when the HFI is completed. For example, if the HFI is completed on a Friday, but shopping happens on Saturdays, what does the presence of certain items in the home mean in terms of obesogeniety? Additional consideration in low-income households is the timing of pay cheques or supplemental income, meaning that families may have less variety at the end of the month when there is less money for food; less food in general; or the food may represent what was available at the local food shelf. These factors can result in a higher obesogenic score. More importantly, it represents limited choice in what foods are available at home. Programmes such as the federal Supplemental Nutrition Assistance Program (SNAP) provide monetary benefits to low-income families to purchase food and offer education and online resources for healthy eating on a budget ${ }^{(30)}$. Although a necessary component, the SNAP is not sufficient for food-insecure families to alleviate obesity risk $^{(31)}$.

The present study showed that the use of formative qualitative research is an effective way to modify tools such as the HFI to match the cultural preferences of a study population. The use of cognitive interviewing may add additional strength to the formative phase. Cognitive interviewing is a guided process in which the interviewer asks the interviewee to verbally describe the cognitive thought process occurring while completing the survey. Cognitive interviewing is useful for questionnaire design as it highlights issues with comprehension, ability of the participant to retrieve the information, decision processes and if the response options are adequate ${ }^{(32)}$. Additionally, insight gained during the formative phase provides useful information for designing interventions. As noted in the results, Spanish-speaking families were concerned that the way they prepare their foods causes obesity, and that they struggle with time demands, work shift complications related to mealtimes and the preferences of their children, all of which have been noted in other families as well $^{(33,34)}$. Given this information, a targeted intervention for Spanish-speaking families could include healthy cooking instruction. We found that Somali-speaking families engage in some health-promoting practices such as limiting pre-packaged and prepared foods as well as sweets and snacks in their homes. However, the Somali families had very few vegetables in the home and were unfamiliar with many common vegetables in the Twin Cities. Somali families could benefit from education on types and preparation techniques for local produce.

An important consideration is what the home food environment means to families that are resource poor and food insecure. For families that are very food insecure, a higher obesogenic score may be necessary if those families need foods that are higher in energy and fat and lower in cost for sustenance, such as regular cheese, milk and processed meats. What is also not known using an HFI is if families with limited access to food at home eat at fast-food restaurants to take advantage of low-cost, energy-dense foods.

The primary limitation of the present study was sample size. In the future, we want to ensure generalizability to Spanish-speaking and/or Somali-speaking adults with children. A power calculation may be useful; however, an overall sense of saturation of responses may be all that is necessary for focus groups. Similarly, future validation work such as this needs to be representative but there are no current statistics about how much change to expect. We also did not collect data on the last grocery shopping trip or timing and source of resources to support purchasing food. We did not ask if families used a food bank or specifically where they shopped, which may be associated with home food availability. We also recognize that there is variability in food habits within and between culture groups. Finally, we did not correlate the HFI with dietary intake or weight. Despite these limitations, we were able to show a process for adapting an existing HFI to two cultural groups that led to a validated and useful tool across populations.

There are other influential food environments that need to be considered in concert with the home food environment. It is likely that children in low-income homes eat more meals at school than non-low-income children. 
Therefore, it could be that an obesogenic home food environment may have less impact on school-aged children or children in day care than on children who are not in pre-school programmes. Finally, it is important to acknowledge that obesity may not be an outcome of interest in households that face food insecurity, housing instability, poor-quality housing and/or the general stress of living with few resources. It is important that interventions related to obesity prevention in this population have knowledge of resources for community food access as well as additional community resources to address other common challenges and stressors related to food, such as transportation challenges and language barriers.

\section{Acknowledgements}

Sources of funding: The present study was supported by the Obesity Consortium at the University of Minnesota. The Obesity Consortium links three obesity centres at the University of Minnesota, including the Obesity Prevention Center (established through the Healthy Foods, Healthy Lives Presidential Initiative), the Minnesota Obesity Center (funded by the National Institute of Diabetes and Digestive and Kidney Diseases) and the Center for Transdisciplinary Research on Energetics and Cancer (funded by the National Cancer Institute). Conflicts of interest: There are no conflicts of interest to report. Authors' contributions: M.O.H. conceived of the idea and was primarily responsible for the data analysis and writing. J.A.F. mentored M.O.H. and provided expertise, writing and editing particularly focused on the validation of the HFI. L.M. provided writing and editing particularly focused on the qualitative aspects of the manuscript. M.P. provided support with the literature review, data management and editing. Acknowledgments: The authors would like to acknowledge Maria Zavala and Mahmoud Farrah who recruited participants and completed the data collection. They also thank all the families who allowed researchers into their home to complete these surveys.

\section{References}

1. US Department of Agriculture \& US Department of Health and Human Services (2010) Dietary Guidelines for Americans, 2010, 7th ed. Washington, DC: USDA.

2. Centers for Disease Control and Prevention (2009) Obesity prevalence among low-income, preschool-aged children United States, 1998-2008. MMWR Morb Mortal Wkly Rep 58, 769-773.

3. Sun SS, Grave GD, Siervogel RM et al. (2007) Systolic blood pressure in childhood predicts hypertension and metabolic syndrome later in life. Pediatrics 119, 237-246.

4. Sun SS, Liang R, Huang TT et al. (2008) Childhood obesity predicts adult metabolic syndrome: the Fels Longitudinal Study. J Pediatr 152, 191-200.

5. Must A, Jacques PF, Dallal GE et al. (1992) Long-term morbidity and mortality of overweight adolescents. A follow-up of the Harvard Growth Study of 1922 to 1935. N Engl J Med 327, 1350-1355.
6. Anderson SE \& Whitaker RC (2009) Prevalence of obesity among US preschool children in different racial and ethnic groups. Arch Pediatr Adolesc Med 163, 344-348.

7. Fitzgibbon ML \& Stolley M (2006) Promoting health in an unhealthful environment: lifestyle challenges for children and adolescents. J Am Diet Assoc 106, 518-522.

8. Sallis JF, Nader PR, Broyles SL et al. (1993) Correlates of physical activity at home in Mexican-American and AngloAmerican preschool children. Health Psychol 12, 390-398.

9. Olstad DL \& McCargar L (2009) Prevention of overweight and obesity in children under the age of 6 years. Appl Physiol Nutr Metab 34, 551-570.

10. Kratt P, Reynolds K \& Shewchuk R (2000) The role of availability as a moderator of family fruit and vegetable consumption. Health Educ Behav 27, 471-482.

11. Raynor HA, Polley BA, Wing RR et al. (2004) Is dietary fat intake related to liking or household availability of high- and low-fat foods? Obes Res 12, 816-823.

12. Cullen KW, Baranowski T, Owens E et al. (2003) Availability, accessibility, and preferences for fruit, $100 \%$ fruit juice, and vegetables influence children's dietary behavior. Health Educ Behav 30, 615-626.

13. Fulkerson JA, Nelson MC, Lytle L et al. (2008) The validation of a home food inventory. Int J Behav Nutr Phys Act 5, 55.

14. Spurrier NJ, Magarey AA, Golley R et al. (2008) Relationships between the home environment and physical activity and dietary patterns of preschool children: a cross-sectional study. Int J Behav Nutr Phys Act 5, 31.

15. Vereecken C, Haerens L, De Bourdeaudhuij I et al. (2010) The relationship between children's home food environment and dietary patterns in childhood and adolescence. Public Health Nutr 13, 1729-1735.

16. French SA, Lin BH \& Guthrie JF (2003) National trends in soft drink consumption among children and adolescents age 6 to 17 years: prevalence, amounts, and sources, 1977/1978 to 1994/1998. J Am Diet Assoc 103, 1326-1331.

17. Downs SM, Arnold A, Marshall D et al. (2009) Associations among the food environment, diet quality and weight status in Cree children in Quebec. Public Health Nutr 12, 1504-1511.

18. Brady LM, Lindquist CH, Herd SL et al. (2000) Comparison of children's dietary intake patterns with US dietary guidelines. Br J Nutr 84, 361-367.

19. Bryant M \& Stevens J (2006) Measurement of food availability in the home. Nutr Rev 64, 67-76.

20. Karp R, Snyder E, Fairorth J et al. (1984) Parental behavior and the availability of foods among undernourished inner-city children. J Fam Pract 18, 731-735.

21. Marsh T, Cullen KW \& Baranowski T (2003) Validation of a fruit, juice, and vegetable availability questionnaire. J Nutr Educ Behav 35, 93-97.

22. Miller C \& Edwards L (2002) Development and validation of a shelf inventory to evaluate household food purchases among older adults with diabetes mellitus. J Nutr Educ Behav 34, 261-267.

23. Crockett SJ, Potter JD, Wright MS et al. (1992) Validation of a self-reported shelf inventory to measure food purchase behavior. J Am Diet Assoc 92, 694-697.

24. Pinard CA, Yaroch AL, Hart MH et al. (2011) Measures of the home environment related to childhood obesity: a systematic review. Public Health Nutr (Epublication ahead of print version).

25. Grigsby-Toussaint DS, Zenk SN, Odoms-Young A et al. (2010) Availability of commonly consumed and culturally specific fruits and vegetables in African-American and Latino neighborhoods. J Am Diet Assoc 110, 746-752.

26. Graham DJ \& Jeffery RW (2011) Location, location, location: eye-tracking evidence that consumers preferentially view prominently positioned nutrition information. J Am Diet Assoc 111, 1704-1711. 
27. Cowburn G \& Stockley L (2005) Consumer understanding and use of nutrition labelling: a systematic review. Public Health Nutr 8, 21-28.

28. Rosenmoller DL, Gasevic D, Seidell J et al. (2011) Determinants of changes in dietary patterns among Chinese immigrants: a cross-sectional analysis. Int J Behav Nutr Phys Act 8, 42.

29. Owens C, Piccinin D \& Lai K (2002) Diabetes in the Somali Community: Cultural Information and Recommendations for Diabetes Educators. http://ethnomed.org/clinical/diabetes/ diabetes-in-the-somali-community-cultural-information-andrecommendations-for-diabetes-educators (accessed January 2012).

30. US Department of Agriculture (2011) Supplemental Nutrition Assistance Program (SNAP). http://www.fns.usda.gov/ snap/ (accessed January 2012).
31. Jilcott SB, Wall-Bassett ED, Burke SC et al. (2011) Associations between food insecurity, supplemental nutrition assistance program (SNAP) benefits, and body mass index among adult females. J Am Diet Assoc 111, $1741-1745$.

32. Willis GB (1999) Cognitive Interviewing: A 'How To' Guide. Durham, NC: Research Triangle Institute.

33. Fulkerson JA, Kubik MY, Rydell S et al. (2011) Focus groups with working parents of school-aged children: what's needed to improve family meals? J Nutr Educ Behav 43, 189-193.

34. Fulkerson JA, Story M, Neumark-Sztainer D et al. (2008) Family meals: perceptions of benefits and challenges among parents of 8- to 10-year-old children. J Am Diet Assoc 108, 706-709. 